\title{
Does combining stimulants combine stimulation?
}

\author{
W. L. ISAAC and W. ISAAC \\ University of Georgia, Athens, Georgia 30602
}

The effects of d-amphetamine and methylphenidate singly and in combination were compared. While a dose-related increase in activity was observed with both drugs, a combination of the drugs showed only the effect of d-amphetamine.

Two drugs that are considered as normally having stimulant effects, d-amphetamine sulfate, or Dexedrine, and methylphenidate hydrochloride, or Ritalin, are commonly used in the treatment of hyperkinesis (Werry \& Sprague, 1970). Both drugs are hypothesized to produce their effects by altering cathecholamine activity.

These drugs produce an increase in locomotor activity in the rat in a dose-related fashion and seem to differ only in their relative potency (Kallman \& Isaac, 1975). Since the drugs produce similar behavioral effects individually and both are assumed to have sympathomimetic effects, it would seem worthwhile to study their combined effects on locomotor activity. It might be expected that their combination would result in the potentiation of their separate effects.

The present study evaluated the consequence of combination of moderate doses of the two drugs upon locomotor activity of the rat. Dose levels of both drugs were employed that have been found to have submaximal effects (Kallman \& Isaac, 1975) and thus would allow the appearance of changes in locomotor activity in either direction upon combination.

\section{METHOD}

Animals

Twelve male albino rats, Sprague-Dawley derived (Southern Animal Farms), served as subjects. They were 20 days old when they arrived in the laboratory and were adapted to the laboratory and daily handling procedure for 7 days. For an additional 15 days, they were adapted to the apparatus, handling, and injection procedures (Isaac \& Isaac, 1977). Food and water were available in the home cages at all times. A 12-h light-dark cycle was maintained in the colony.

\section{Apparatus}

The subjects were housed in clear plastic mouse-breeding cages $45 \mathrm{~cm}$ long, $24 \mathrm{~cm}$ wide, and $25 \mathrm{~cm}$ high, with a hardware cloth cover during activity measurements. Each plastic container was housed in a separate sound-treated cubicle, open at one end, that was $85 \mathrm{~cm}$ deep, $56 \mathrm{~cm}$ wide, and $56 \mathrm{~cm}$ high and individually lighted with a 20 -W fluorescent bulb mounted $29 \mathrm{~cm}$ above the floor of the activity chamber. The 12 cubicles were housed in a sound-treated room.

This work was supported by Grant MH 25164 from the National Institute of Mental Health.
A single infrared light beam bisected the length of each plastic container about $2 \mathrm{~cm}$ above the floor and fell upon a photocell. An infrared filter covered the photocell, making it insensitive to ambient illumination. When the subjects broke the beam in their chambers, counts were recorded on individual counters in a separate room.

\section{Procedure}

Five drug conditions were studied. Placebo injections of bacteriostatic water, the vehicle for each of the five drug conditions, were included to give a total of six experimental conditions. Two dose levels of methylphenidate hydrochloride, 1.6 and $3.2 \mathrm{mg} / \mathrm{kg}$, two dose levels of d-amphetamine sulfate, .4 and $.8 \mathrm{mg} / \mathrm{kg}$, and a combination, $.4 \mathrm{mg} / \mathrm{kg}$ d-amphetamine sulfate and $1.6 \mathrm{mg} / \mathrm{kg}$ methylphenidate hydrochloride, were studied. All injections were given in equal volume of $1 \mathrm{ml} / \mathrm{kg}$ and were administered intraperitoneally 5-10 min before the subjects were placed in the activity measurement apparatus. Subjects were weighed every 3 days.

Six separate orders of daily drug administrations were utilized, thus producing a 6 by 6 Latin square with two subjects within each order. All subjects were run through their orders three times. The first replication was allowed for adaptation to the effect of the drug injections, and only scores from the last two replications were compared and evaluated by analysis of variance.

Upon being placed in the plastic containers, all equipment was turned on and $5 \mathrm{~min}$ were allowed for adaptation. Activity measures were obtained for the next $60 \mathrm{~min}$. Activity scores were transformed by a $\sqrt{\mathrm{x}+1}$ transformation, as recommended for frequency scores (Edwards, 1972).

\section{RESULTS}

The data obtained (Figure 1) were evaluated by analysis of variance, with the main effects compared to their interactions with subjects. The difference between replications was not significant $[\mathrm{F}(1,11)=3.94, \mathrm{p}>.05]$, nor was the interaction between the drug conditions and replications significant $[F(5,55)=1.25, \mathrm{p}>.05]$. The activity levels seen under the drug conditions, however, did differ significantly $[F(5,55)=55.82$, $\mathrm{p}<.01]$.

The differences among the drug conditions were further evaluated using Duncan's Multiple Range Test (Edwards, 1972). This analysis, with alpha set at the 1\% level, indicated that the placebo condition produced the least activity, and the smaller dose of methylphenidate produced a significant increase in activity. While 


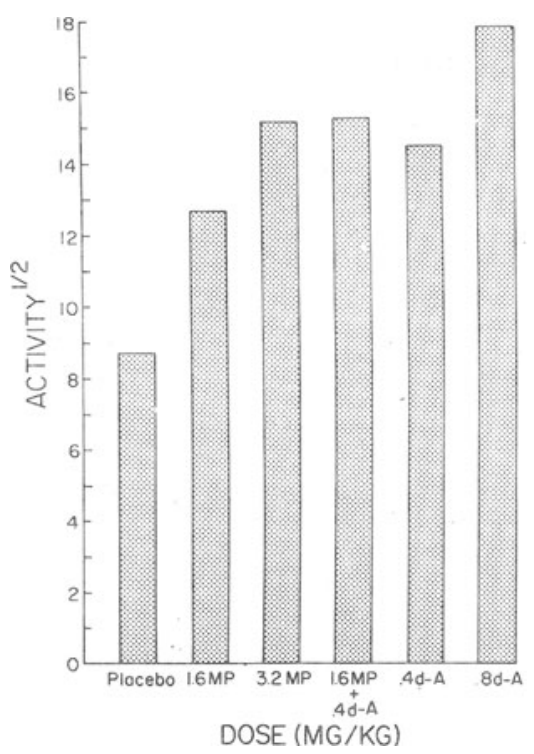

Figure 1. The effects of the drug conditions on square-root transformed locomotor activity scores in the rat.

the conditions of $4 \mathrm{mg} / \mathrm{kg}$ d-amphetamine, $3.2 \mathrm{mg} / \mathrm{kg}$ methylphenidate, and the combined dose of $.4 \mathrm{mg} / \mathrm{kg}$ d-amphetamine and $1.6 \mathrm{mg} / \mathrm{kg}$ methylphenidate produced an increase in activity that was significantly greater than the lower dose of methylphenidate, they did not differ among themselves. The highest dose of d-amphetamine produced a statistically significant higher level of activity than all other conditions. Thus it was found that both doses of both drugs produced dose-related increases in locomotor activity. As has been found previously (Kallman \& Isaac, 1975), d-amphetamine was the more potent of the two drugs. Combining doses of the drugs yielded no interactive effect.

\section{DISCUSSION}

Since both drugs are thought to act upon the adrenergic mechanisms (Moore, Carr, \& Dominic, 1970; Schmitt \& Schmitt,
1970), it was expected that the combination of the drugs would result in an increased activity level when compared to either drug given singly. Intermediate dose levels of both drugs (Kallman \& Isaac, 1975) were chosen, so that changes in activity in either direction, as the consequence of the combination of the drugs, could be detected. Since the higher dose of d-amphetamine produced a still greater increase in activity than the combined dose, it is apparent that a "ceiling" effect was not operating. And since both the placebo and low dose of methylphenidate produced less activity than the combined dose, results were not limited in that direction.

The effects of the combined dose did not differ from the effects of $.4 \mathrm{mg} / \mathrm{kg} \mathrm{d}$-amphetamine alone. The lack of an increase in activity above the level of $.4 \mathrm{mg} / \mathrm{kg}$ of $\mathrm{d}$-amphetamine by the addition of $1.6 \mathrm{mg} / \mathrm{kg}$ of methylphenidate was surprising. Since they are used interchangeably in the clinical setting because of their similar effects (Werry \& Sprague, 1970), both have sympathomimetic effects (Moore et al., 1970; Schmitt \& Schmitt, 1970), and both produce similar changes in the locomotor activity of the rat (Kallman \& Isaac, 1975), a potentiation of their individual effects was expected.

\section{REFERENCES}

EDWARDS, A. L. Experimental design in psychological research. New York: Holt, Rinehart, \& Winston, 1972.

IsAAC, W. L., \& IsAAC, W. Differences in placebo effects. Pharmacology, Biochemistry and Behavior, 1977, 6, 235-236.

Kallman, W. M., \& IsaAc, W. The effects of age and illumination on the dose-response curves for three stimulants. Psychopharmacologia, 1975, 40, 313-318.

Moore, K. E., CARr, L. A., \& Dominic, J. A. Functional significance of amphetamine-induced release of brain catecholamines. In E. Costa \& S. Garattini (Eds.), Amphetamine and related compounds. New York: Raven Press, 1970.

Schmitт, H., \& Schmitr, H. Interactions between reserpine and amphetamine on blood pressure. In E. Costa \& S. Garattini (Eds.), Amphetamine and related compounds. New York: Raven Press, 1970.

WerRy, J., \& SPRAgue, R. Hyperactivity. In C. Costello (Ed.), Symptoms of psychopathology. New York: Wiley, 1970.

(Received for publication September 12, 1978.) 